\title{
The Synthesis of Magnesium Soaps as Feed for Biohydrocarbon Production
}

\author{
Meiti Pratiwi ${ }^{1, *}$, Godlief F. Neonufa ${ }^{1,2}$, Tirto Prakoso ${ }^{1}$, and Tatang H. Soerawidjaja ${ }^{1}$ \\ ${ }^{1}$ Department of Chemical Engineering, Institut Teknologi Bandung, Bandung 40132, Indonesia \\ ${ }^{2}$ Department of Agriculture Product Technology, Universitas Kristen Artha Wacana, Kupang 85000, Indonesia
}

\begin{abstract}
In previous study, by heating magnesium basic soaps from palm stearine will decarboxylated and produced biohydrocarbon. The frequent method to produced metal soaps from triglyceride in laboratory scale is metathesis. This process is less favored because this method would produced large amounts of salt waste and hard to develop into bigger scale. This study investigated the process and characterization of magnesium soaps from coconut oil and magnesium hydroxide via direct reaction method at $185{ }^{\circ} \mathrm{C}$ for 3 and 6 hours. The resulting soaps were washed with water and methanol, then dried. This process yield more than $80 \%-w$ metal soaps, acid values lower than $6 \mathrm{mg} \mathrm{KOH} / \mathrm{g}$ and $\mathrm{pH}$ 9.2. Based on Thermogravimetry Analysis (TGA) and SEM results, the initial decomposition temperature of these metal soaps were at $300{ }^{\circ} \mathrm{C}$ and have amorphous surface morphology. From decarboxylation test of magnesium basic soaps indicate great potency as feed for biohydrocarbon production.
\end{abstract}

\section{Introduction}

Metal soaps, or metal long-chain carboxylates, are alkaline-earth or heavy-metal salts of carboxylic acids with carbon atoms 7-22 [1,2]. Application of metal soaps are diverse such as heat stabilizers for plastics (especially polyvinyl chloride, or PVC), driers in paint or inks, waterproofing agents, fuel additives, cosmetic products, component as lubricating greases, etc [2-6]. Most of these applications are related to the thermal properties of metal soaps [7]. Metal soaps could also use as feed for thermal decomposition to produce biohydrocarbon $[8,9]$.

Fatty acids and vegetable oil are the feed for metal soaps manufacture. The metal soaps manufacture processes using fatty acids as saponification feed are precipitation process, or double decomposition; fusion process, direct reaction of fatty acids, or carboxylic acids, with metal oxides, hydroxides, and carbonates; and direct reaction of metals and molten fatty acids $[1,4,10]$. Fatty acids as saponification feed has greater cost compare to triglycerides derived from vegetable oil, because it is more expensive. Therefore, production metal soaps from vegetable oil is more attractive.

The general method to produce metal soaps derived from vegetable oil is metathesis process [11-13]. This process was started by mixing the vegetable oil and hot ethanol, then stirred the mixture with sodium hydroxide $20 \%$ (w/w) solution, become aqueous sodium soaps. This sodium soap is then added the metal aqueous solution (example metal nitrate, acetate, chloride, and sulfate) and yield metal soaps. This process produced sodium nitrate/acetate/chloride/sulfate as waste so it is difficult to develop this process into larger scale. Therefore, this research was carried out by direct reaction of triglyceride and metal hydroxide, as described by $[14,16]$. The zinc soaps were produced from the reaction mixture of zinc oxide/hydroxide, water, and triglycerides at elevated temperature. The by-product from direct reaction method is glycerine [14], which is valuable.

The metal soaps produced by direct reaction [14] were stoichiometry soaps (formula: $\mathrm{M}(\mathrm{RCOO})_{2}$, if bivalent metals). This experiment aimed to obtained basic soaps (formula: $\mathrm{M}(\mathrm{RCOO})(\mathrm{OH})$, if bivalent metal and use hydroxide as saponification feed) because the metal soaps would be the feed for decarboxylation process to produce hydrocarbon (Reaction 1). The decomposition reaction of stoichiometric metal soaps would produce ketones (Reaction 2) [3].

$$
\begin{aligned}
& \mathrm{M}(\mathrm{RCOO})(\mathrm{OH}) \rightarrow \mathbf{R H}+\mathrm{MCO}_{3}(1) \\
& \mathrm{M}(\mathrm{RCOO})_{2}+\mathrm{M}\left(\mathrm{R}^{\prime} \mathrm{COO}\right)_{2} \rightarrow 2 \text { RCOR' }+2 \mathrm{MCO}_{3}(2)
\end{aligned}
$$

In previous research [12-14], the main product from decarboxylation of magnesium basic soaps from palm stearin and palm kernel oil were green diesel and biokerosene.

Corresponding author: mei@che.itb.ac.id 
One of vegetable oils produced in Indonesia is coconut oil (Cocos nucifera). The main fatty acid constituent of coconut oil is lauric acid (C12:0) [11], as palm kernel oil. The preparation and characterization of metal soaps derived from coconut oil was performed by [11] using metathesis process.

The objective of this research was to investigate the characteristics of magnesium basic soaps carried out by direct reaction of coconut oil and magnesium hydroxide. The resulting basic soaps were characterization the acid value, $\mathrm{pH}$, thermal decomposition, morphology, and metal content of magnesium basic soaps. This research also conducted decarboxylation test of magnesium basic soaps to obtain the yield of liquid products.

\section{Experimental}

Coconut oil (Barco) was used in the experiment with acid value/AV 0,6 mg KOH/g and consisted of caprylic acid (5,92\%-mol), capric acid $(6,08 \%)$, lauric acid (42,39\%), myristic acid (20\%), palmitic acid (11,41\%), stearic acid $(3,72 \%)$, oleic acid $(8,94 \%)$, and linoleic acid $(1,54 \%)$. Magnesium hydroxide was prepared by co-precipitation process of $\mathrm{MgNO}_{3} \cdot 6 \mathrm{H}_{2} \mathrm{O}$ with sodium hydroxide (Merck), as described in [16].

The reaction was carried out at $185^{\circ} \mathrm{C}$ for 3 and 6 hours under vigorous stirring, by reacting coconut oil (1 mol), magnesium hydroxide (3 mol), and water (excess). The magnesium soaps were washed with distilled water and methanol, filtered, and dried overnight at $60{ }^{\circ} \mathrm{C}$. The dried soaps was ground into magnesium basic soaps powder. Saponification process was performed in $100 \mathrm{ml}$ stainless steel mini-autoclave. For simplicity, magnesium basic soaps obtained were given code $\mathrm{Mg}$ $\mathrm{CO}-3$ (for $3 \mathrm{~h}$ reaction) and $\mathrm{Mg}-\mathrm{CO}-6$ (for $6 \mathrm{~h}$ reaction).

$\mathrm{pH}$ of magnesium soaps was tested by added $2 \mathrm{~g}$ soaps into $20 \mathrm{ml}$ distilled water, stirred, then measured the $\mathrm{pH}$ with $\mathrm{pH}$-meter digital until the $\mathrm{pH}$ was stable. The free fatty acids content of magnesium basic soaps was analyzed using Cunder method [17,18]. Thermogravimetric analysis (Linseis STA PT 1600) of magnesium basic soaps was carried out by heating the sample from 30 until $700{ }^{\circ} \mathrm{C}$ at constant heating rate 10 ${ }^{\circ} \mathrm{C} / \mathrm{min}$ under nitrogen gas flow at $40 \mathrm{ml} / \mathrm{min}$. A scanning electron microscope (SEM) with energydispersive X-ray (EDX) analyses was used to identify the morphology and metal content of soaps. The magnesium basic soaps were coated with gold using the sputtering technique.

The decarboxylation test of magnesium basic soaps was performed in $100 \mathrm{ml}$ glass batch reactor at atmospheric pressure. Decarboxylation reaction was carried out from room temperature up to $370^{\circ} \mathrm{C}$ and maintained for 5 hours at that temperature. 9-10 g magnesium basic soaps were placed into the reactor. Before heating, the reactor was flushed with nitrogen to remove the remaining oxygen inside. The heat was supplied from heating mantle. The condensed products from decarboxylation reactor, or liquid products, were collected in a beaker and measured. The series of decarboxylation equipment and aparatus used in this experiment is same as [12,13].

\section{Results and discussion}

\subsection{Synthesis and characterization of Magnesium Soaps}

The yields magnesium basic soaps carried out by direct reaction of magnesium hydroxide and coconut oil for 3 and 6 hours are 92.23 and $88.23 \%-w$. Both soaps are white and light, similar with magnesium stearate commercial grade. Magnesium basic soaps obtained from this process has similar physical characteristic with magnesium soaps of coconut oil reported by Ek [11]. This is prove that the direct reaction could produce magnesium basic soaps of coconut oil with good yield.

The result acid value and $\mathrm{pH}$ of magnesium basic soaps are given in Table 1. These magnesium basic soaps have acid value below $6 \mathrm{mg} \mathrm{KOH} / \mathrm{g}$ sample, which there were free fatty acids in these basic soaps. The free fatty acids contained in metal soaps indicated the phenomena of direct reaction, triglycerides hydrolysis into free fatty acids then these acids were reacted with $\mathrm{Mg}^{2+}$ ion (soluble in water) and formed magnesium soaps. $\mathrm{pH}$ magnesium basic soaps about 9.2, higher than magnesium stoichiometric soaps obtained by Ek [11], 8.2. This $\mathrm{pH}$ confirmed that direction reaction used in this experiment successfully produce magnesium basic soaps of coconut oil.

Table 1. Acid value and $\mathrm{pH}$ of magnesium basic soaps

\begin{tabular}{|c|c|c|}
\hline Sample & $\begin{array}{c}\mathrm{AV} \\
(\mathrm{mg} \mathrm{KOH} / \mathrm{g})\end{array}$ & $\mathrm{pH}$ \\
\hline $\mathrm{Mg}-\mathrm{CO}-3$ & 5.39 & 9.20 \\
\hline $\mathrm{Mg}-\mathrm{CO}-6$ & 2.91 & 9.21 \\
\hline
\end{tabular}

The TGA curve (Figure 1) show that these magnesium basic soaps have similar thermal behavior. These magnesium basic soaps were lose their moisture up to $110^{\circ} \mathrm{C}$, and then stable from $110-350{ }^{\circ} \mathrm{C}$. From $300-500$ ${ }^{\circ} \mathrm{C}$, the basic soaps were decomposed very rapidly and show small weight change during further increased temperature. Thermal decomposition of magnesium basic soaps is written in Reaction 1, which yield magnesium carbonate as residue. Further heating with increased temperature would decompose magnesium carbonate into magnesium oxide and carbon dioxide. The final residue weight of magnesium basic soaps was similar with the weight of magnesium oxide. It is important to studied decomposition behavior so the thermal characteristic and decarboxylation reaction temperature can be predicted. 


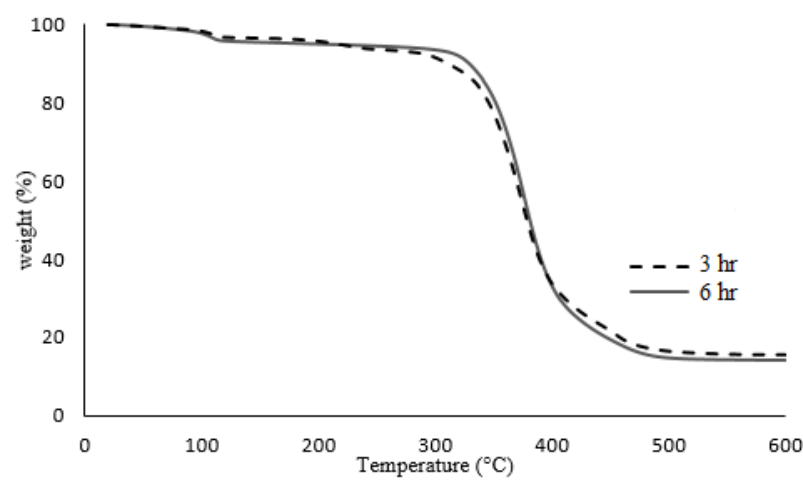

Fig. 1. TGA curve of magnesium basic soaps

The magnesium soaps of coconut oil morphology has not been studied. SEM analysis were conducted to know the morphology of magnesium basic metal soaps. The morphology of magnesium basic soap particles is shown in Figure 2 and 3. The magnesium basic soaps of coconut oil exhibit amorphous morphology, except the particles from $\mathrm{Mg}-\mathrm{CO}-6$ were more packed than $\mathrm{Mg}$ CO-3 particles. It might be caused by longer saponification reaction.

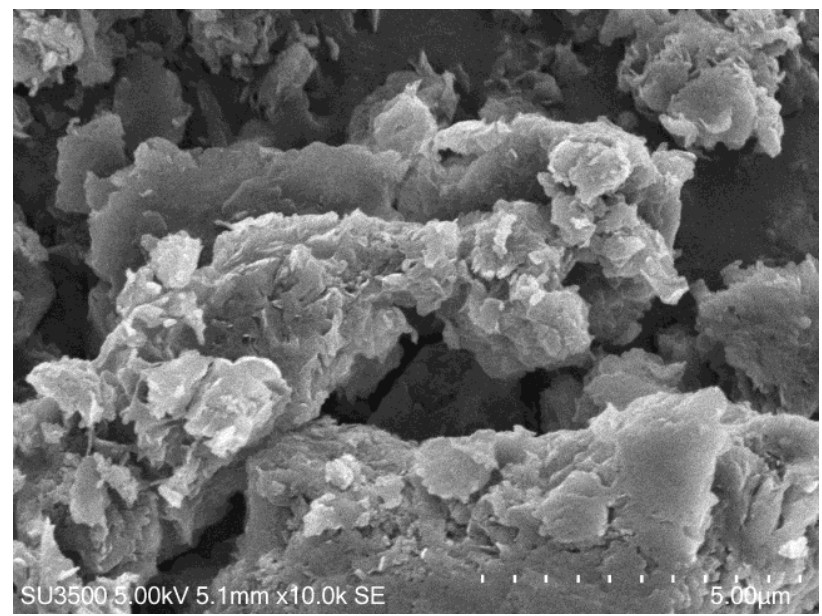

Fig. 2. SEM micrographs of Mg-CO-3

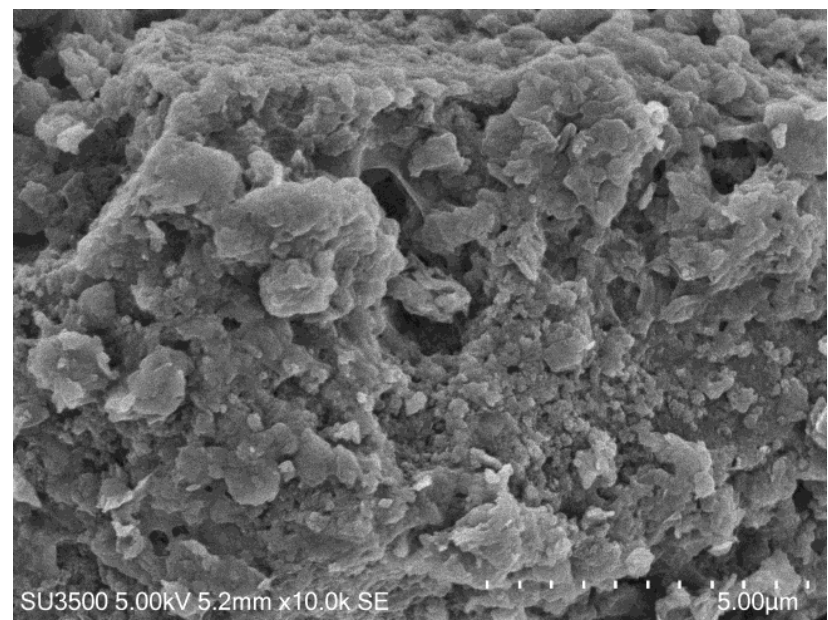

Fig. 3. SEM micrographs of Mg-CO-6
EDX is a powerful tool for analyze the elements content, especially for elements with atomic number greater than four [5]. The detector scanned the observed area to identified the elements contained in magnesium basic soaps particles and their spreading. It also detected gold, but neglected because the sample particles were coating with gold. Both soaps contained three common elements : carbon, oxygen, and magnesium. The elements spread almost evenly at magnesium basic soaps surface particles (Figure 4 and 5).

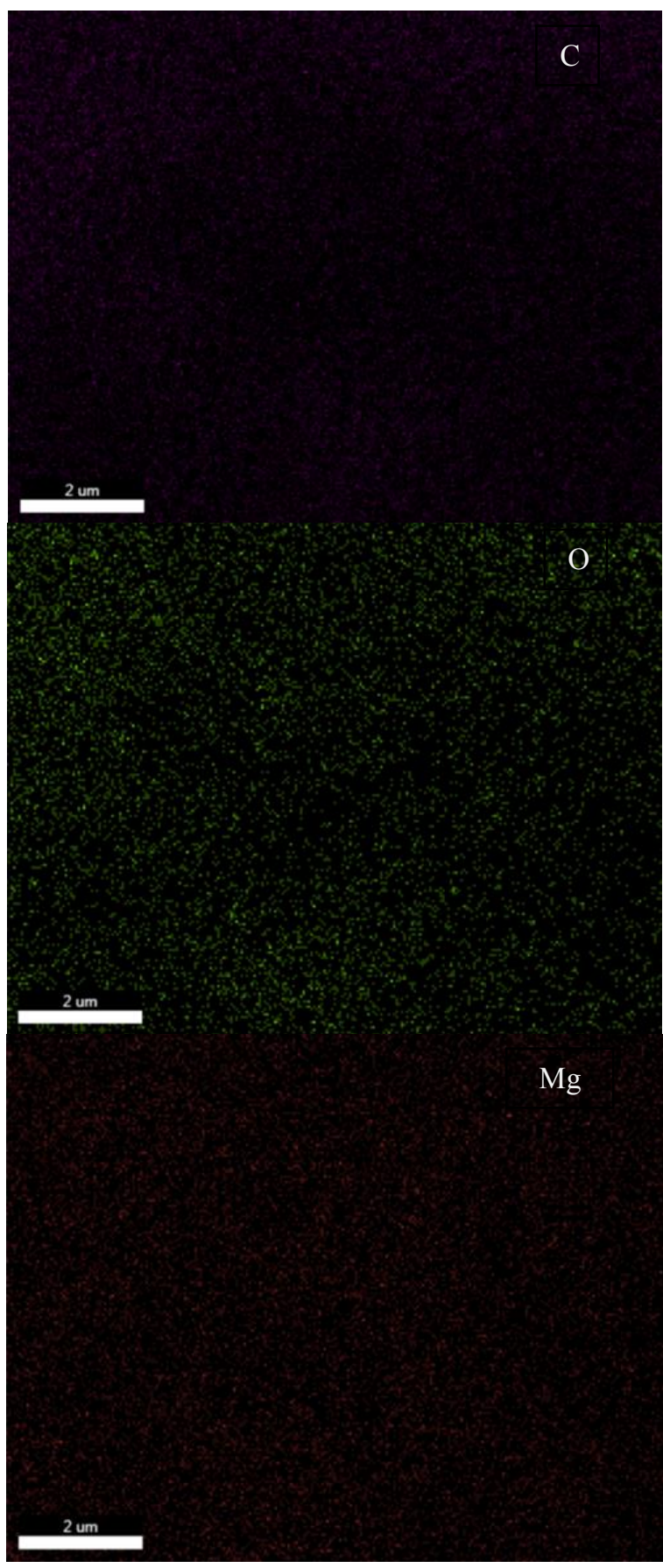

Fig. 4. The element spreading in $\mathrm{Mg}-\mathrm{CO}-3$ particles 


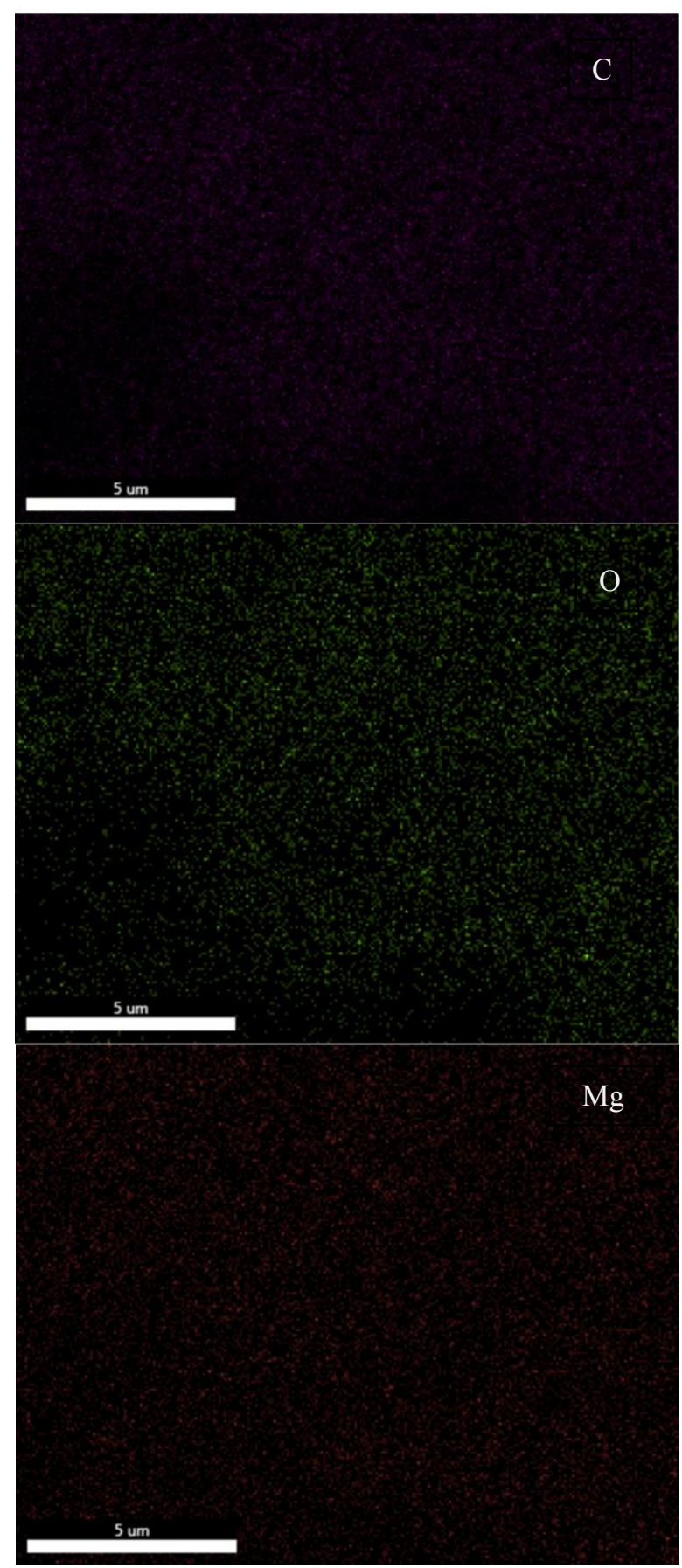

Fig. 5. The element spreading in $\mathrm{Mg}-\mathrm{CO}-6$ particles

Table 2 show the EDX measurements of magnesium basic soaps of coconut oil prepared by direct reaction and theoritical values of elements contained, on hydrogen free basis. EDX analysis only give an indication of the element content in the metal soaps since it measured based on the area observed. From the comparison of the experimental results obtained for the soaps prepared using direct reaction method, both magnesium soaps have $\mathrm{C}$ and $\mathrm{Mg}$ slight higher than theoritical values. A possible explanation for this result could be from free fatty acids, indicated from acid value analysis. The acid value of $\mathrm{Mg}-\mathrm{CO}-3$ is slighty higher than $\mathrm{Mg}-\mathrm{CO}-6$, so the $\mathrm{C}$ content of $\mathrm{Mg}-\mathrm{CO}-3$ is higher.
Table 2. The element content in magnesium basic soaps.

\begin{tabular}{|l|r|r|r|}
\hline \multirow{2}{*}{ Element } & \multicolumn{3}{|c|}{$\%$-w } \\
\cline { 2 - 4 } & Theoritical & \multicolumn{1}{c|}{ Mg-CO-3 } & Mg-CO-6 \\
\hline $\mathrm{C}$ & 58.59 & 64.09 & 63.6 \\
\hline $\mathrm{O}$ & 23.40 & 20.84 & 22.9 \\
\hline $\mathrm{Mg}$ & 17.99 & 15.07 & 13.5 \\
\hline
\end{tabular}

\subsection{Decarboxylation Test of Magnesium Basic Soaps}

The products obtained from decarboxylation of magnesium basic soaps were liquid product, water, solid residue, and other (include gas), show in Table 2. Up to $100{ }^{0} \mathrm{C}$, water was collected from beaker. The liquid product color obtained from decarboxylation magnesium basic soaps at $370^{\circ} \mathrm{C}$ for $5 \mathrm{~h}$ is yellow-brown liquid. The yield product was measured by compare the weight of liquid product with theoritical hydrocarbon could obtained. Regardless the liquid product yield still varied (62.75 and $31.51 \%-w)$, it indicated that magnesium could be used as feed for bio-hydrocarbon production. When compared with other processes to produce biohydrocarbon from vegetable oil, such as via hydrodeoxygenation [19], decarboxylation of metal basic soaps is a potential alternative process to produce biohydrocarbon because it performed at atmospheric pressure and not using noble metals as catalyst.

Table 2. Products of Mg-CO decarboxylation

\begin{tabular}{|c|c|c|c|c|c|}
\hline \multirow[t]{2}{*}{ Feed } & \multicolumn{4}{|c|}{$[\%-w t]$} & \multirow{2}{*}{$\begin{array}{l}\text { Yield } \\
\text { liquid } \\
\text { product } \\
(\%)\end{array}$} \\
\hline & Residue & Water & Others & $\begin{array}{l}\text { Liquid } \\
\text { product }\end{array}$ & \\
\hline $\begin{array}{c}\mathrm{Mg}-\mathrm{CO}- \\
3 \\
\end{array}$ & 39.76 & 0.86 & 20.6 & 38.78 & 62.75 \\
\hline $\begin{array}{c}\mathrm{Mg}-\mathrm{CO}- \\
6\end{array}$ & 59.49 & 1.09 & 19.62 & 19.8 & 31.51 \\
\hline
\end{tabular}

\section{Conclusion}

In this study, the direct reaction of coconut oil and magnesium hydroxide was investigated to obtain magnesium basic soaps. The reaction was carried out at $185{ }^{\circ} \mathrm{C}$ in the presence of water, and the processes occurred in this method was hydrolysis of triglycerides hydrolysis into free fatty acids/ffa and saponification reaction between ffa with magnesium ion soluble in water, formed magnesium soaps which insoluble in water. The addition of saponification reaction time did not give significant effect, based on the amount of yield, $\mathrm{pH}$, free fatty acids content, thermal behavior, and surface morphology of magnesium basic metal soaps. Thermal decomposition of magnesium basic soaps was examined in TGA analysis, it concluded that there only occurred one decomposition cycle from $300^{\circ} \mathrm{C}$.

Decarboxylation of magnesium basic soaps at $370{ }^{\circ} \mathrm{C}$ for $5 \mathrm{~h}$ produced liquid product, predicted as biohydrocarbon, as main product. This decarboxylation 
product need further identification. The decarboxylation process was carried out at atmospheric pressure, moderate temperature, low hydrogen consumption, and not using noble catalyst, such as platina or palladium, indicate the potential of this process as alternative method to produce biohydrocarbon.

We acknowledge the support from P3MI.

\section{References}

1. S. B. Elliott, The Alkaline-Earth and Heavy-Metal Soaps (Reinhold Publishing Corporation, New York, 1946)

2. Q. Dou, K. M. Ng. Powder Technology 301 (2016)

3. M. S. Akanni, E. K. Okoh, H. D. Burrows, H. A. Ellis, Thernochim. Acta 208 (1992)

4. M. Gönen, D. Balköse, F. Ïnal, S. Ülkü, Ind. Eng. Chem. Res. 44 (2005)

5. T. O. Egbuchunam, D. Balköse, F. E. Okieimen, Polymer Degradation and Stabillity 92 (2007)

6. D. Balköse, T. O. Egbuchunam, F. E. Okieimen, J. Therm. Anal. Calorim. 101 (2010)

7. R. Sharma, L. C. Heda, A. Joram, Physical Chemistry (2013)

8. C. C. Chang, S. W. Wan, Ind. Eng. Chem 39 (1947)

9. H. Lappi, R. Alen, Journal of Analytical and Applied Pyrolysis 91 (2011)

10. K. S. Markley, Fatty Acids Their Chemistry, Properties, Production, and Uses (Interscience Publishers Inc., 1961)

11. O. Ek, J. Appl. Sci. Environ. Manage 18, 2 (2014)

12. G. F. Neonufa, M. Pratiwi, T. H. Soerawidjaja, T. Prakoso, Proceeding of International Seminar on Chemical Engineering in conjunction with STKSR (2016)

13. G. F. Neonufa, M. Pratiwi, A. N. Istyami, L. Elizabeth, S. S. Dewi, R. Purwadi, Proceeding of IJCAET (2016)

14. J. Blachford, US Patent No 4,316,852 (1982)

15. L. H. Duong, O. Fujita, I. K. Reksowardojo, T. H. Soerawidjaja, G. F. Neonufa, Fuel 185 (2016)

16. M. Pratiwi, P. Ylitervo, A. Pettersson, T. Prakoso, T. H. Soerawidjaja, Proceeding of SOMCHE 2016 (2016)

17. R. E. Laily, dan J. Cunder, US Patent No. 3,476,786. (1969)

18. R. D. Borzelli, dan J. Cunder, US Patent No. 4,307,027 (1981)

19. E. Santilan-Jimenes, M. Crocker, J Chem Technol Biotechnol, 87 (2012) 